\title{
Productos estrella en Centroamérica entre imaginarios, exportaciones y mitos. Un análisis cuantitativo y comparativo del banano y el café en Honduras y Costa Rica:
}

1970-1976

\section{Star products in Central America between imaginary, exports and myths. A quantitative and comparative banana and coffee in Honduras and Costa Rica analysis: 1970-1976}

Antonio Ramón Vallejo Cerna ${ }^{3}$

\section{Resumen}

Durante gran parte del siglo XX, el banano y el café se constituyeron como los principales productos de exportación de los países del área centroamericana, el primero para el caso hondureño y el segundo para el caso costarricense respectivamente. El cultivo, la producción y exportación de estos productos generó en dichas economías espacios de poder y control social que llevó como consecuencia a la promoción de diversos escenarios históricos a nivel económico, político, social y cultural en la región durante esa época. Esto generó y reforzó en el imaginario social la creencia de que Honduras es aún

${ }^{3}$ Catedrático de la carrera de Ciencias Sociales de la Universidad Pedagógica Nacional Francisco Morazán. Egresado de la Maestría A cadémica en Historia de la Universidad de Costa Rica. Correo electrónico: avallejo1985@gmail.com 
un país eminentemente exportador de banano y Costa Rica de café en los mercados internacionales. Al hacer un análisis comparativo de estos productos podremos observar ciertas tendencias que revelan que debido a las coyunturas políticas y ambientales durante el período de estudio (1970-1976) se produj o una transición en dichas economías a convertirse el café en el producto de exportación más importante de Honduras y el banano en Costa Rica.

Palabras clave: banano, café, control social, exportaciones, imaginario social.

Abstrac: During a great part of the XX century, Banana and coffee were constituted as the principal products of exportation in countries of the Central American area, the first for the Honduran case and the second for the Costa Rican respectively. The crops, production and exportation of these products generated on such economies, spaces of power and social control that brought as a consequence the promotion of diverse historical scenarios to the economic, political, social and cultural levels in the region during that age. This generated and enforced the social imaginary, the belief that Honduras is still an eminent banana exporter and Costa Rica as a coffee exporter in the international markets. By doing a comparative analysis of these products we can observe certain tendencies that reveal that due to the political and environment joints during the period of study (1970-1976) a transition was produced in such economies and turned coffee into the most important product of exportation of Honduras and the banana in Costa Rica.

Key words: Banana, coffee, social control, exportations, social imaginary.

\section{Breve reseña de como el café y el banano se convirtieron en los principales productos de exportación de Honduras y Costa Rica.}

Para finales del siglo XIX -específicamente para la década de 1870 en adelante-, y motivados bajo los preceptos del liberalismo económico de prosperidad, progreso y la creación de una sociedad y economía moderna, Centroamérica se caracterizó por la 
Productos estrella en Centroamérica entre imaginarios, exportaciones y mitos. Un análisis cuantitativo y comparativo del banano y el café en Honduras y Costa Rica: 1970-1976

implementación del modelo agroexportador o de desarrollo hacia afuera. Eso ocasionó a que los Estados centroamericanos realizaran esfuerzos por incentivar el cultivo de materias primas, pues para la época la demanda de las mismas aumentó en Estados Unidos y Europa. Esto llevaría como consecuencia a una dependencia de los vaivenes de la economía mundial que más adelante repercutirá en las dinámicas políticas y sociales de los países centroamericanos. El cultivo del café tuvo predominancia en países como Guatemala y Costa Rica, en cambio en Honduras prevaleció la siembra del banano.

Sin embargo, es importante mencionar que desde 1870 se intentó impulsar la producción de café distribuyendo tierras en las tierras altas de los departamentos de Santa Bárbara, Comayagua, Copán, El Paraíso, Tegucigalpa y Choluteca; no obstante, los jornaleros y labradores prefirieron continuar con sus cultivos de subsistencia y con los productos tradicionales de exportación que se vendían en los mercados vecinos. De igual forma los programas del gobierno para el cultivo del café se dan en un momento de débil demanda mundial de este producto, en contraste con el crecimiento en la producción de banano generada en la costa norte de Honduras. Para 1892 los informes consulares británicos son reveladores: el café constituyó solamente el 2.2\%total de las exportaciones de Honduras superadas por la minería, la actividad ganadera y la exportación de bananos y cacao. (Ver Cuadro No.1)

\section{Cuadro No.1}

Tipos, valores y porcentajes de las exportaciones en Honduras: 1892

\begin{tabular}{|l|c|c|}
\hline \multicolumn{1}{|c|}{ Artículos } & $\begin{array}{c}\text { Valores } \\
\text { (en miles de Dólares) }\end{array}$ & Porcentaje \% \\
\hline Plata & 732,059 & 39.6 \\
\hline Ganado & 667,339 & 35.6 \\
\hline Bananos & 211,939 & 11.3 \\
\hline Cacao & 91,989 & 4.9 \\
\hline Café & 41,393 & 2.2 \\
\hline Tabaco (manufacturado) & 27,104 & 1.4 \\
\hline Tabaco crudo & 22,208 & 1.1 \\
\hline Zarzaparrilla & 19,883 & 1 \\
\hline
\end{tabular}


Antonio Ramón Vallejo Cerna

\begin{tabular}{|l|c|c|}
\hline Oro & 19,657 & 1 \\
\hline Sombreros de Paja & 16,916 & 0.9 \\
\hline Otros productos Manufacturados & 6,930 & 0.3 \\
\hline Hule de Ia India & 6,861 & 0.3 \\
\hline Madera (caoba y cedro) & 6,758 & 0.3 \\
\hline Otros productos agrícolas & $\mathbf{2 , 7 6 2}$ & 0.1 \\
\hline Total & $\mathbf{1 , 8 7 3 , 7 9 8}$ & $\mathbf{1 0 0}$ \\
\hline
\end{tabular}

Fuente: Elaboración propia en base a los documentos de Commercial Reports,

Papers Relating to Honduras 1893. Pág. 41

Con el paso de los años, el banano se convertirá en el producto de exportación más sobresaliente en Honduras, con la particularidad que el capital extranjero poco a poco desplazará a los pequeños productores que iniciaron este comercio. Es notable observar como la United Fruit Compañy (UFCO) se convertirá en una de las empresas más poderosas e influyentes en la política y economía hondureña durante gran parte del siglo XX. En cambio, en Costa Rica nos encontramos con la diferencia que desde finales de la Colonia hasta mediados del siglo XIX el Estado comienza a expropiar tierras que eran destinados a la ganadería en cafetales -entre ellos a pueblos indígenas-, especialmente las tierras localizadas en el valle central. De esta forma observamos el florecimiento de varias fincas dedicadas al cultivo del café con salarios atractivos por la escasez de mano de obra ${ }^{4}$.

\section{El café y el banano en los imaginarios sociales centroamericanos.}

Durante el siglo XX la economía hondureña dependerá de la exportación del banano, a tal punto que las empresas transnacionales definirán la política del país, colocando presidentes e influyendo en el Congreso de la República para obtener favores especiales. De esta manera a Honduras se le denominó con el apelativo de "Banana Republic" o República Bananera, donde sus características eran ser países dependientes de un monocultivo, altamente corruptos

\footnotetext{
${ }^{4}$ A lo largo del período de 1870 a 1930 Costa Rica logró una balanza comercial favorable contrario a Honduras. Es decir, el valor de las exportaciones era mayor al costo total de los productos importados.
} 
y administrado por caudillos. Ejemplo de este apelativo lo encontramos en administraciones como la de Manuel Bonilla, Tiburcio Carías Andino o la de Oswaldo López Arellano.

En cambio en Costa Rica con la consolidación de la clase terrateniente, especialmente en el valle central, observamos un auge en la producción así como una relación entre desarrollo y el trabajo en los campos de café. Esto llevó a cada uno de los países en estudio a la construcción de imaginarios en donde cada uno tendrá su identidad como países agroexportadores y a la vez a generar diferenciaciones que con el paso del tiempo llevarán a la idea de depender exclusivamente de estos productos.

\section{Década de 1970: época de cambios en las economías hondureñas y costarricenses.}

En 1967 el Estado hondureño crea la Asociación Hondureña de Productores de Café (AHPROCAFE), demostrando el interés del Estado por impulsar de nuevo la producción de café dirigido especialmente a los pequeños y medianos productores. El banano, producto por excelencia de exportación hasta ese momento no estaba rindiendo lo necesario como otrora fue en el pasado. (Recordemos que Honduras en 1929 se convirtió en el exportador número 1 de banano) Además que la mayoría de las ganancias por la exportación del banano se quedaba con las empresas transnacionales. Esto sugiere a la vez que se estaría gestando muy tardíamente una élite agraria en Honduras.

Otro antecedente de suma importancia política fue en el año de 1969 donde gobierno de Honduras -por medio de la junta militarimpulsa una serie de medidas en el agro con el propósito de hacerlas productivas, debido a la amenaza que presentaban las intenciones de los terratenientes salvadoreños en crear conflictos entre los campesinos de Honduras y El Salvador, ocupando tierras del territorio hondureño impulsando el conflicto bélico de 100 horas entre estas dos naciones. Bien podría esto significar un elemento más de tener en cuenta al momento de los análisis económicos comparativos.

Otro antecedente político de importancia para la región es que en 
el período de estudio, en Honduras se gestaron tres golpes de Estado por parte de los militares, mientras que Costa Rica gozaba de una democracia consolidada.

Cabe señalar que el año de 1974, fue un año decisivo en el comportamiento de las exportaciones del banano y el café tanto en Honduras como en Costa Rica, ya que el primero fue azotado por el paso del huracán Fifí, destruyendo en gran parte las plantaciones de banano que están ubicadas en la zona costera del norte del país, -a diferencia de las plantaciones de café que en ese momento no sufrieron daño al estar ubicadas en su mayoría en la zona occidental del país-; mientras tanto en Costa Rica la Asamblea Legislativa fijaba un precio fijo hacia el banano, con el cual incentivaba una economía estable para este producto, no dejándolo al libre albedrío de las fluctuaciones económicas, que a diferencia de los demás países centroamericanos se estaban gestando.

Otro de los aspectos que debemos tener en cuenta al momento del análisis es la situación de la economía mundial. Recordemos que es en esta década que se comienza una nueva crisis del petróleo en el mundo y menos exigencias del sector primario de la economía.

\section{Cuadro No.2}

Exportaciones de banano entre Honduras y Costa Rica 1970-1976 en miles de dólares

\begin{tabular}{|c|c|c|c|c|c|c|c|}
\hline País & $\mathbf{1 9 7 0}$ & $\mathbf{1 9 7 1}$ & $\mathbf{1 9 7 2}$ & $\mathbf{1 9 7 3}$ & $\mathbf{1 9 7 4}$ & $\mathbf{1 9 7 5}$ & $\mathbf{1 9 7 6}$ \\
\hline Honduras & 75,710 & 95,680 & 93,160 & 93,990 & 79,700 & 61,450 & 106,700 \\
\hline Costa Rica & 66,677 & 63,888 & 82,833 & 90,672 & 98,002 & 144,072 & 142,602 \\
\hline
\end{tabular}

Fuente: Ellis, Frank "Las transnacionales del banano en Centroamérica", San José, 1983

Como se mencionó anteriormente, en 1974 es un año decisivo para el impulso de las exportaciones del banano en Costa Rica, aprovechando el paso del huracán Fifí en Honduras. A partir de este año hasta 1976 -que es el período de estudio- Costa Rica le llevará mucha ventaj a a Honduras. Lo podemos observar mej or en el grafico No. 1 
Productos estrella en Centroamérica entre imaginarios, exportaciones y mitos. Un análisis cuantitativo y comparativo del banano y el café en Honduras y Costa Rica: 1970-1976

Gráfico No. 1

Comportamiento de las exportaciones del banano entre Honduras y Costa Rica 1970-1976

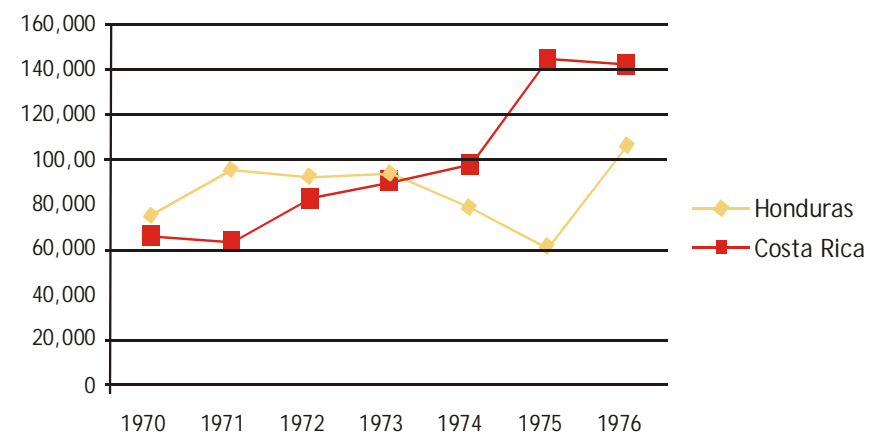

Fuente: Elaboración propia en base a datos del cuadro No. 2

Cuadro No. 3

Exportaciones de café entre Honduras y Costa Rica en miles de dólares 1970-1976

\begin{tabular}{|c|c|c|c|c|c|c|c|}
\hline País & $\mathbf{1 9 7 0}$ & $\mathbf{1 9 7 1}$ & $\mathbf{1 9 7 2}$ & $\mathbf{1 9 7 3}$ & $\mathbf{1 9 7 4}$ & $\mathbf{1 9 7 5}$ & $\mathbf{1 9 7 6}$ \\
\hline Honduras & 94.19 & 87.24 & 77.8 & 110.77 & 131.44 & 108.20 & 214.01 \\
\hline Costa Rica & 73.1 & 59.02 & 77.7 & 94.0 & 125.02 & 96.7 & 154.2 \\
\hline
\end{tabular}

Fuente: Para Honduras: Banco Central de Honduras, 1996. Para Costa Rica: Pérez Héctor, y Samper Mario "Tierra, Café y Sociedad" San J osé, 1993

Es interesante observar cómo se da una constante de precios de exportación del café en Honduras, a diferencia de Costa Rica que muestra una fluctuación en ciertos años. Esto en cierta medida desmitifica el hecho de que el café era el producto de mayor importancia en Costa Rica, así como el del banano en Honduras. En otras palabras, el banano pasa a ser el producto de más importancia para Costa Rica, así como el café lo fue para Honduras en los años de estudio. En el gráfico No. 2 podemos observar el comportamiento de los precios del café en estos dos países. 


\section{Gráfico No. 2}

Comportamiento de las exportaciones del café entre Honduras y Costa Rica 1970-1976

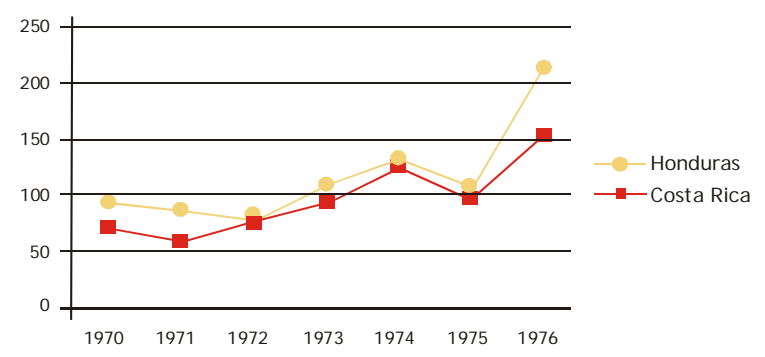

Fuente: Elaboración propia en base a datos del cuadro No.2

\section{Gráfico No. 3}

Comparación entre las exportaciones del banano y el café en Honduras en miles de dólares 1970-1976

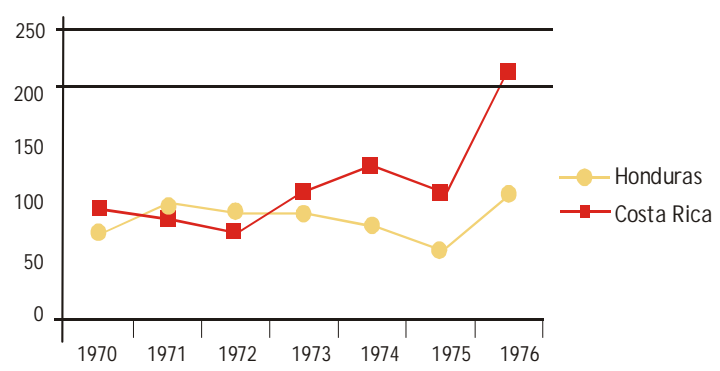

Fuente: Elaboración propia en base a datos del cuadro No 2 y 3

Para el caso hondureño se puede ilustrar de una mejor forma el comportamiento de las exportaciones del café en comparación con el banano, donde las primeras son más altas que las últimas. Mientras que en el gráfico No. 4 que corresponde al caso costarricense se demuestra lo contrario: un repunte de las exportaciones del banano en comparación con el café, aunque de una forma más pareja. 
Productos estrella en Centroamérica entre imaginarios, exportaciones y mitos. Un análisis cuantitativo y comparativo del banano y el café en Honduras y Costa Rica: 1970-1976

\section{Gráfico No. 4}

Comparación entre las exportaciones del banano y el café en Honduras en miles de dólares 1970-1976

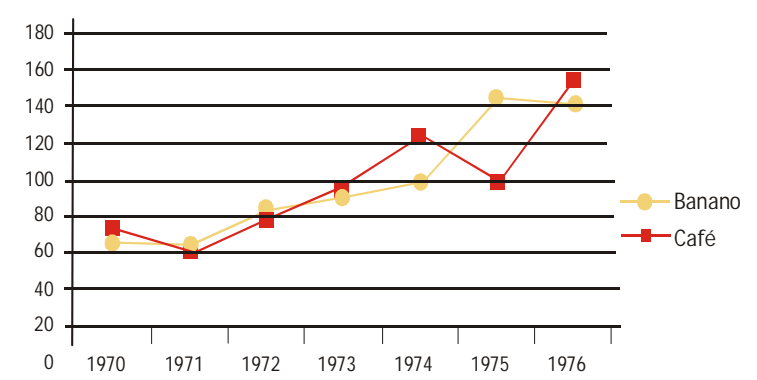

Fuente: Elaboración propia en base a datos del cuadro No 2 y 3

\section{Conclusiones}

En Honduras a diferencia de los demás países de la región centroamericana, no contaba con una élite agraria consolidada. Sin embargo, por el número de las exportaciones de un producto como el café que estaba incentivado por el Estado demuestra que bien se estaba formando una nueva clase económica agraria, y por el cual el mismo sería de mucha importancia para la economía nacional.

El aumento de las exportaciones del banano en Costa Rica podría significar un protagonismo del mismo en mucho tiempo en Centroamérica.

La inestabilidad política de Honduras, frente a la estabilidad democrática de Costa Rica, el paso del huracán Fifí y el impacto ecológico en las plantaciones de banano en Honduras, pudieron ser motivos por los cuales el banano tuvo un auge en las exportaciones en Costa Rica.

Las transformaciones operadas principalmente desde mediados de los años 1970 y posteriormente en los años 1980, permitieron a considerar a Honduras como un país cafetalero y con tendencias a colocarse entre los principales productores de café de Centroamérica. 
Antonio Ramón Vallejo Cerna

\section{Referencias Bibliografícas}

Banco Central de Honduras "Honduras en cifras: informe de la producción de café de 1996" Tegucigalpa, 1996.

Ellis, Frank "Las transnacionales del banano en Centroamérica", San J osé, 1983.

Guevara Escudero, José "Honduras en el siglo XIX: su historia socioeconómica: 1839-1914" editorial UPNFM, Tegucigalpa, 2007.

Pérez Héctor, y Samper Mario "Tierra, Café y Sociedad" San José, 1993. 